\title{
Network meta-analysis of eribulin versus other chemotherapies used as second- or later-line treatment in locally advanced or metastatic breast cancer
}

Qi Zhao ${ }^{1}$, Rachel Hughes ${ }^{2}$, Binod Neupane ${ }^{3}$, Kristin Mickle ${ }^{4}$, Yun Su ${ }^{5}$, Isabelle Chabot ${ }^{6}$, Marissa Betts ${ }^{4}$ and Ananth Kadambi ${ }^{2 *}$ (i)

\begin{abstract}
Background: Eribulin mesylate (ERI; Halaven $\left.{ }^{\oplus}\right)$ is a microtubule inhibitor approved in the United States for metastatic breast cancer patients with at least two prior chemotherapy regimens for metastatic breast cancer, and in the European Union in locally advanced breast cancer or metastatic breast cancer patients who progressed after at least one chemotherapy for advanced disease. This network meta-analysis compared the efficacy and safety of ERI versus other chemotherapies in this setting.

Methods: Systematic searches conducted in MEDLINE, Embase, and the Cochrane Central Register of Clinical Trials identified randomized controlled trials of locally advanced breast cancer/metastatic breast cancer chemotherapies in second- or later-line settings. Efficacy assessment included pre-specified subgroup analysis of breast cancer subtypes. Included studies were assessed for quality using the Centre for Reviews and Dissemination tool. Bayesian network meta-analysis estimated primary outcomes of overall survival and progression-free survival using fixedeffect models. Comparators included: capecitabine (CAP), gemcitabine (GEM), ixabepilone (IXA), utidelone (UTI), treatment by physician's choice (TPC), and vinorelbine (VIN).

Results: The network meta-analysis included seven trials. Results showed that second- or later-line patients treated with ERI had statistically longer overall survival versus TPC (hazard ratio [HR]: 0.81; credible interval [Crl]: 0.66-0.99) or GEM+VIN (0.62; 0.42-0.90) and statistically longer progression-free survival versus TPC $(0.76 ; 0.64-0.90)$, but statistically shorter progression-free survival versus CAP+IXA (1.40; 1.17-1.67) and CAP+UTI (1.61; 1.23-2.12). In triple negative breast cancer, ERI had statistically longer overall survival versus CAP $(0.70 ; 0.54-0.90)$; no statistical differences in progression-free survival were observed in triple negative breast cancer.

Conclusions: This network meta-analysis suggests that ERI may provide an overall survival benefit in the overall locally advanced breast cancer/metastatic breast cancer populations and triple negative breast cancer subgroup compared to standard treatments. These findings support the use of ERI in second- or later-line treatment of patients with locally advanced breast cancer/metastatic breast cancer.
\end{abstract}

\footnotetext{
* Correspondence: ananth.kadambi@evidera.com

${ }^{2}$ Evidence Synthesis, Modeling \& Communication, Evidera, San Francisco, CA, USA

Full list of author information is available at the end of the article
}

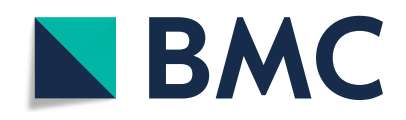

(- The Author(s). 2021 Open Access This article is licensed under a Creative Commons Attribution 4.0 International License, which permits use, sharing, adaptation, distribution and reproduction in any medium or format, as long as you give appropriate credit to the original author(s) and the source, provide a link to the Creative Commons licence, and indicate if changes were made. The images or other third party material in this article are included in the article's Creative Commons licence, unless indicated otherwise in a credit line to the material. If material is not included in the article's Creative Commons licence and your intended use is not permitted by statutory regulation or exceeds the permitted use, you will need to obtain permission directly from the copyright holder. To view a copy of this licence, visit http://creativecommons.org/licenses/by/4.0/. The Creative Commons Public Domain Dedication waiver (http://creativecommons.org/publicdomain/zero/1.0/) applies to the data made available in this article, unless otherwise stated in a credit line to the data. 
Keywords: Breast cancer, Metastatic, Locally advanced, Network meta-analysis, Triple negative breast cancer, overall survival

\section{Background}

The prognosis of locally advanced breast cancer $(\mathrm{LABC}) /$ metastatic breast cancer $(\mathrm{MBC})$ depends heavily on patient and disease characteristics (e.g., tumor size, extent of lymph node involvement, sites of metastases, hormone receptor and human epidermal growth factor receptor 2 (HER2) status, and presence of an inflammatory component) [1, 2]. Treatment of $\mathrm{LABC} / \mathrm{MBC}$ in the second- or later-line $(2 \mathrm{~L}+)$ setting aims to provide maximum control of symptoms, prevent serious complications, prolong survival, delay disease progression, and maintain quality of life [3]. Selection of treatment in these lines depends on several factors, including hormone receptor (HR) and HER2 status, aggressiveness of the disease, type of prior therapy, and response to prior therapy [3].

Eribulin mesylate (ERI; Halaven ${ }^{\circ}$ ) is a microtubule inhibitor indicated for the treatment of $L A B C / M B C$ in patients who have previously received at least two chemotherapy (ChT) regimens for $\mathrm{MBC}$ in the United States (US), and for the treatment of LABC/MBC in patients who have progressed after at least one ChT for advanced disease in the European Union (EU). Approval for $2 \mathrm{~L}+$ treatment was granted by the European Medicines Agency (EMA) in 2011 [4], and approval as a third- or later-line $(3 \mathrm{~L}+)$ treatment for MBC was granted by the US Food and Drug Administration (FDA) in 2010 [5]. In both regions, patients should have received prior treatment with anthracyclines or taxanes, unless they were not suitable. ERI has a novel mode of action that is distinct from other tubulin-targeting agents such as taxanes and vinca alkaloids; it exclusively binds to the growing positive ends of tubulin without affecting its normal function, which might explain how ERI is able to overcome taxane resistance and have a potentially wider clinical effect [6].

A systematic literature review (SLR) was conducted to identify and synthesize available randomized controlled trial (RCT) evidence on the efficacy and safety of ChTs used in patients who have received one or more previous systemic therapies in the LABC/MBC setting. Bayesian network meta-analysis (NMA) was then used to compare the relative efficacy and safety of ERI as a $2 \mathrm{~L}+$ treatment for $\mathrm{LABC} / \mathrm{MBC}$ versus other ChTs in the overall population and in subgroups of triple negative breast cancer (TNBC) and HR-positive/HER2-negative populations.

\section{Methods}

\section{Identification and selection of studies}

The review followed methodology outlined in a prespecified study protocol and adhered to Preferred Reporting Items for Systematic Reviews and MetaAnalyses (PRISMA) guidelines [7, 8]. Systematic searches were conducted to identify peer-reviewed RCTs published from 1 January 2007 to 22 March 2019 in Embase, MEDLINE (via PubMed), and the Cochrane Library. Search strategies included a combination of controlled vocabulary including relevant medical subject headings and free-text terms such as 'breast cancer', 'breast neoplasm', 'metastasis', and 'locally advanced'. The full search strategies describing the population, study design, and treatment search parameters are presented in Additional file 1. Conference proceedings of five key meetings from the 2 years prior to preparation of this manuscript (2018 to 2019) were searched, including the American Society of Clinical Oncology (ASCO), the European Society of Medical Oncology (ESMO), the Japan Society of Clinical Oncology, the Japan Society of Medical Oncology, and the International Society for Pharmacoeconomics and Outcomes Research (ISPOR). Conference proceedings from the above meetings were hand-searched using free-text terms for 'breast cancer'. Additionally, bibliographies of identified SLRs were also searched manually to confirm that all relevant studies were included.

Screening was conducted using pre-defined eligibility criteria that were based on population, interventions, comparisons, outcomes, and study design (PICOS; Table 1). At the title/abstract level, all abstracts were screened by one investigator, and a second reviewer examined $10 \%$ of exclusions to validate screening quality of the first reviewer. Full-text screening was conducted by two independent investigators, with discrepancies resolved by a third investigator. The primary outcomes of interest were overall survival (OS), progression-free survival (PFS), rate of treatment discontinuation due to adverse events (TDAEs), and rate of serious adverse events (SAEs). Comparators of interest for inclusion in the NMA were monotherapy and combination strategies of: capecitabine (CAP), gemcitabine (GEM), ixabepilone (IXA), utidelone (UTI), vinorelbine (VIN), and treatment by physician's choice (TPC).

\section{Data extraction and assessment}

Data from RCTs that met the eligibility criteria were extracted by one reviewer, and a second reviewer validated 
Table 1 PICOS Criteria for Study Selection

\begin{tabular}{|c|c|c|}
\hline PICOS & Inclusion Criteria & Exclusion Criteria \\
\hline Population & $\begin{array}{l}\text { Patients with } \mathrm{LABC} \text { or } \mathrm{MBC} \text { who had received at least } \\
\text { one prior therapy } \\
-\mathrm{LABC} \text { or } \mathrm{MBC} \text { defined as stage } \mathrm{IV} \text {, any } \mathrm{T} \text {, and } \mathrm{N}, \mathrm{M1}^{\text {a }} \\
\text { Target populations were HER2-negative or } \mathrm{TNBC} \text {, but } \\
\text { HER2-positive populations were also included }\end{array}$ & $\begin{array}{l}\therefore \text { Early disease (stage I-III) } \\
\therefore \text { First-line treatment }\end{array}$ \\
\hline Interventions & 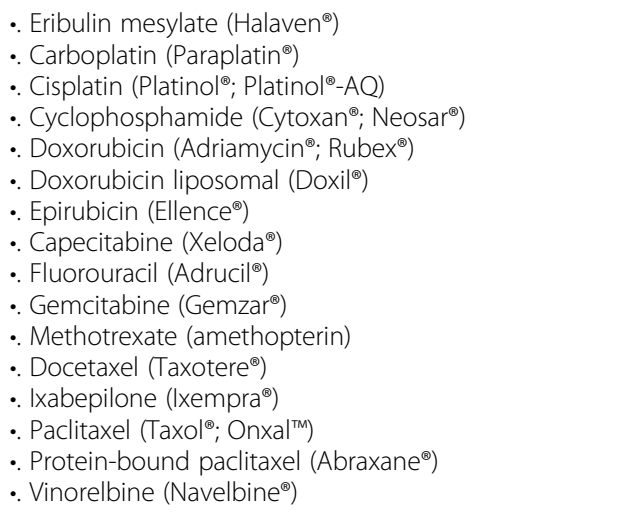 & $\begin{array}{l}\text { Interventions not of interest or administered in combination with } \\
\text { interventions of interest }\end{array}$ \\
\hline Comparators & $\begin{array}{l}\mathrm{BSC} \text {, placebo, or all therapies listed above as } \\
\text { monotherapy or in combination with other treatments } \\
\text { for } \mathrm{LABC} / \mathrm{MBC}\end{array}$ & \\
\hline Outcomes & $\begin{array}{l}\text { - Efficacy: OS, PFS, response (including ORR, CR, PR, SD, } \\
\text { PD) } \\
\text { - Safety: AEs, SAEs, discontinuation, and death }\end{array}$ & Studies not reporting any outcomes of interest \\
\hline $\begin{array}{l}\text { Study } \\
\text { Design }\end{array}$ & RCTs & $\begin{array}{l}\text { Observational studies (including but not limited to case controls, } \\
\text { prospective and retrospective cohorts, cross-sectional studies, single-arm } \\
\text { trials, SLRs, NMAs, dose-escalation studies) }\end{array}$ \\
\hline Countries & Any & NA \\
\hline
\end{tabular}

Abbreviations: AE Adverse event, BSC Best supportive care, $C R$ Complete response, HER2 Human epidermal growth factor receptor 2, $L A B C$ Locally advanced breast cancer, $M B C$ Metastatic breast cancer, NA Not applicable, NMA Network meta-analysis, ORR Objective response rate, OS Overall survival, PD Progressive disease, PFS Progression-free survival, PICOS Population, interventions, comparisons, outcomes, and study design, PR Partial response, RCT Randomized controlled trial, SAE Serious adverse event, SD Stable disease, SLR Systematic literature review, TNBC Triple-negative breast cancer

${ }^{a}$ Any size, with or without nearby lymph node involvement, spread to distant organs or distal lymph nodes

the extraction for accuracy. Data fields of interest included study design (e.g., trial phase and blinding), methods, sample size, disease and patient characteristics, intervention details (e.g., dosage, schedule), study followup and assessment time periods, and efficacy and safety outcomes. The quality of RCTs was assessed using the Centre for Reviews and Dissemination tool according to the National Institute for Health and Care Excellence (NICE) Guide to the Methods of Technology Appraisal [9].

Evidence identified from the SLR was assessed to determine the feasibility of comparing efficacy and safety estimates via an NMA. The network of evidence for each outcome of interest was assessed, and the need for and validity of any assumptions required to connect the network was evaluated. Specifically, the feasibility assessment evaluated whether RCTs were comparable with regards to factors that impact the relative effect of each of the treatments on each outcome, including patient-level characteristics, relevancy of interventions (comparable dosage and schedules), availability of outcome data overall and by subgroup (e.g., TNBC, HR-positive/HER2-negative, number of prior lines of therapy), outcome definitions, and timepoints at which outcomes were assessed.

Connected networks that included ERI and at least a subset of comparators for key efficacy and safety outcomes were identified and are presented in Figs. 1, 2, 3, $4,5,6,7,8$. Direct head-to-head efficacy and safety comparisons versus ERI were available for CAP and TPC, and other comparators were compared indirectly. Studies reporting treatment with VIN monotherapy, docetaxel (DOC) monotherapy, GEM+DOC, and CAP+DOC were identified by the SLR, but did not connect to the networks.

\section{Descriptive analyses and Bayesian NMA approach}

Following recommendations from the feasibility assessment, the Bayesian NMA included scenario analyses to explore the potential impact of suspected effect modifiers from clinical heterogeneity across trial 


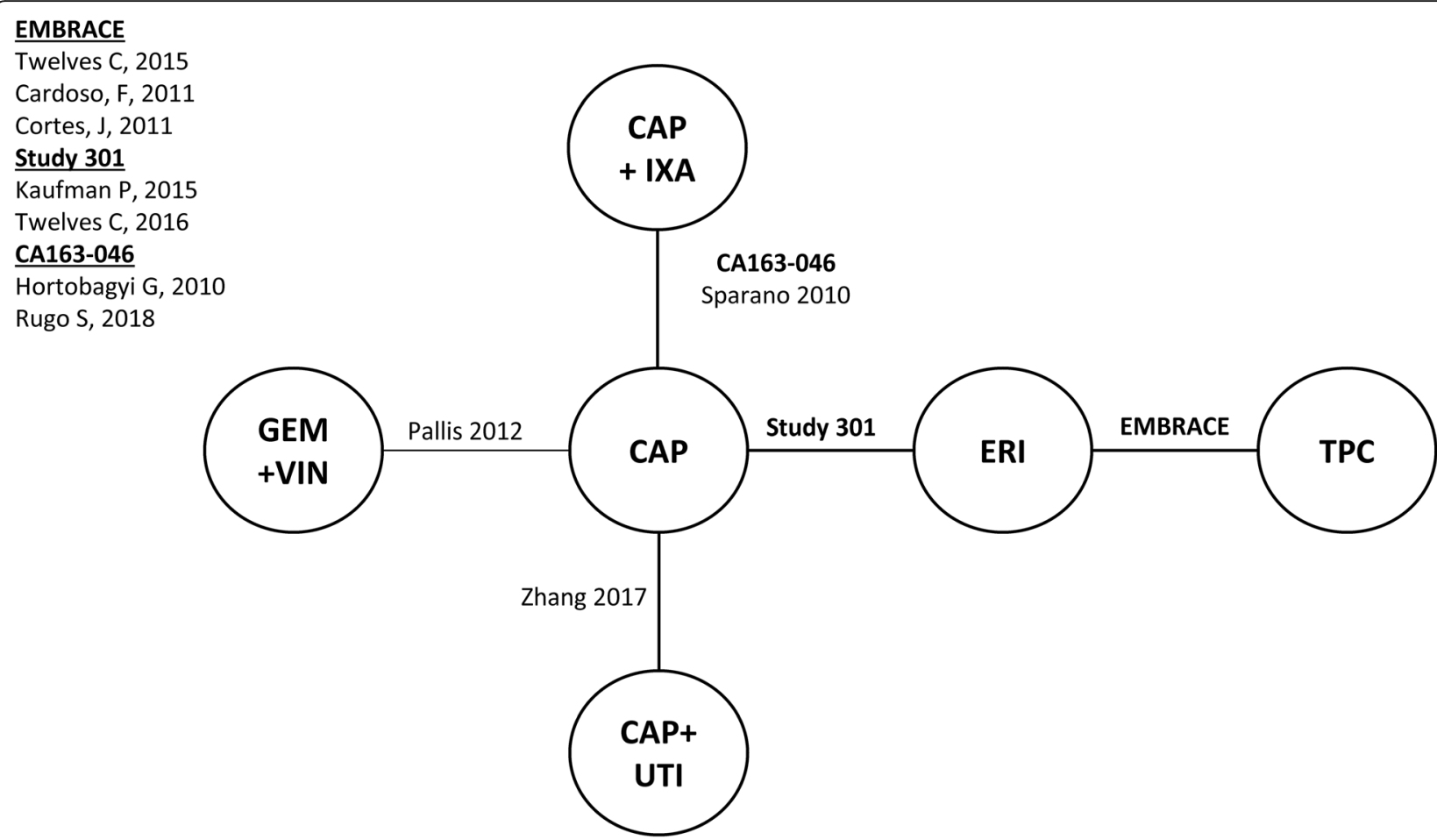

Fig. 1 Network Diagram: Overall Survival (Base-case Analysis). Abbreviations: $C A P=$ capecitabine; $E R I=$ eribulin; $G E M=$ gemcitabine; IXA = ixabepilone; TPC = treatment by physician's choice; UTI = utidelone; VIN = vinorelbine

populations and within subgroups. For example, we conducted subgroup analyses for TNBC and HRpositive/HER2-negative patients. Subgroup analyses by line of therapy were also planned for patients receiving treatment in the $2 \mathrm{~L}+$ versus $3 \mathrm{~L}+$ setting, but ultimately not conducted due to a lack of data allowing for this stratification, as discussed further below (see "Results").
In each analysis, estimates for ERI versus each comparator of interest were obtained using long-established Bayesian NMA techniques $[10,11]$. A fixed-effect model was used as the primary analysis approach for each outcome due to limited heterogeneity between trials; however, if two or more studies were available for at least one treatment comparison that showed some evidence of heterogeneity (i.e., when pairwise $\mathrm{I}^{2} \geq 25 \%$, where $\mathrm{I}^{2}$ is the percentage of

\section{EMBRACE}

Cortes, J, 2011

Study 301

Twelves C, 2016

CA163-046

Hortobagyi G, 2010

Rugo S, 2018

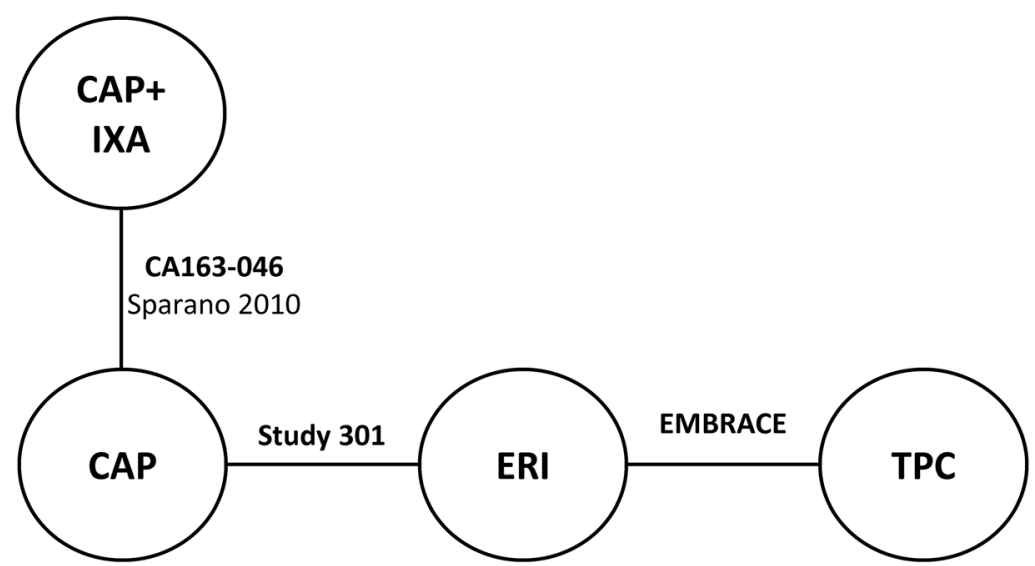

Fig. 2 Network Diagram: Overall Survival (TNBC Subgroup Analysis). Abbreviations: CAP = capecitabine; ERI = eribulin; IXA = ixabepilone; TNBC = triple negative breast cancer; TPC = treatment by physician's choice 


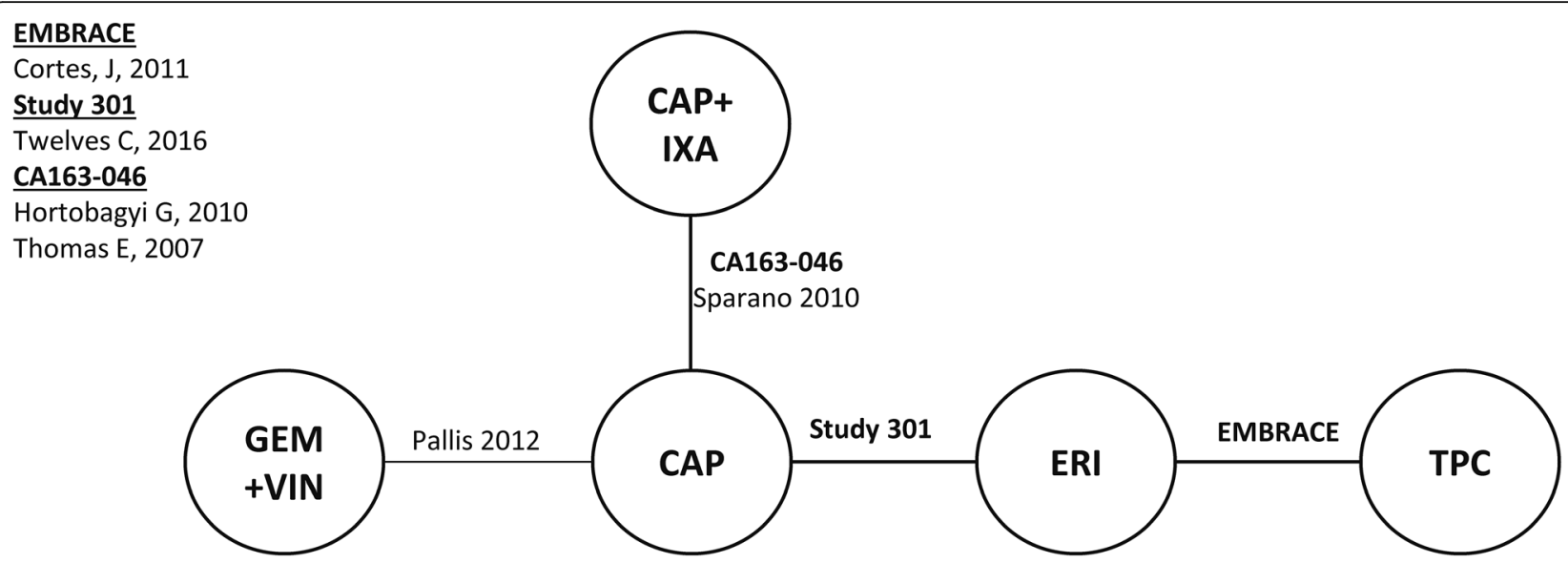

Fig. 3 Network Diagram: Overall Survival (HER2-negative Subgroup Analysis). Abbreviations: $C A P=$ capecitabine; ERI = eribulin; GEM = gemcitabine; IXA = ixabepilone; TPC = treatment by physician's choice; VIN = vinorelbine

variation in the treatment estimates between studies beyond change), a random-effect model was employed.

All Bayesian analyses were conducted in OpenBUGS 3.2.3, with 100,000 iterations for "burn-in" and 100,000 iterations for the posterior inference. Each NMA provided an estimate of the relative treatment effect (e.g., a hazard ratio $[\mathrm{HR}]$ for OS and PFS or an odds ratio [OR] for SAEs, along with a 95\% credible interval [CrI]). Throughout the results, the terminology 'statistical difference' or 'statistically' are used in instances where CrIs for HRs or ORs do not include 1.

\section{Results}

Systematic literature review Study selection

The SLR searches identified 5942 records for title/abstract screening after duplicate removal. Of these, 429 articles were screened for full-text eligibility and 45 publications representing 28 unique RCTs were included in the SLR. Of the 28 RCTs identified by the SLR, 21 trials were excluded from the NMA for the following reasons: 12 trials investigated treatments not of clinical interest for the NMA (olaparib,

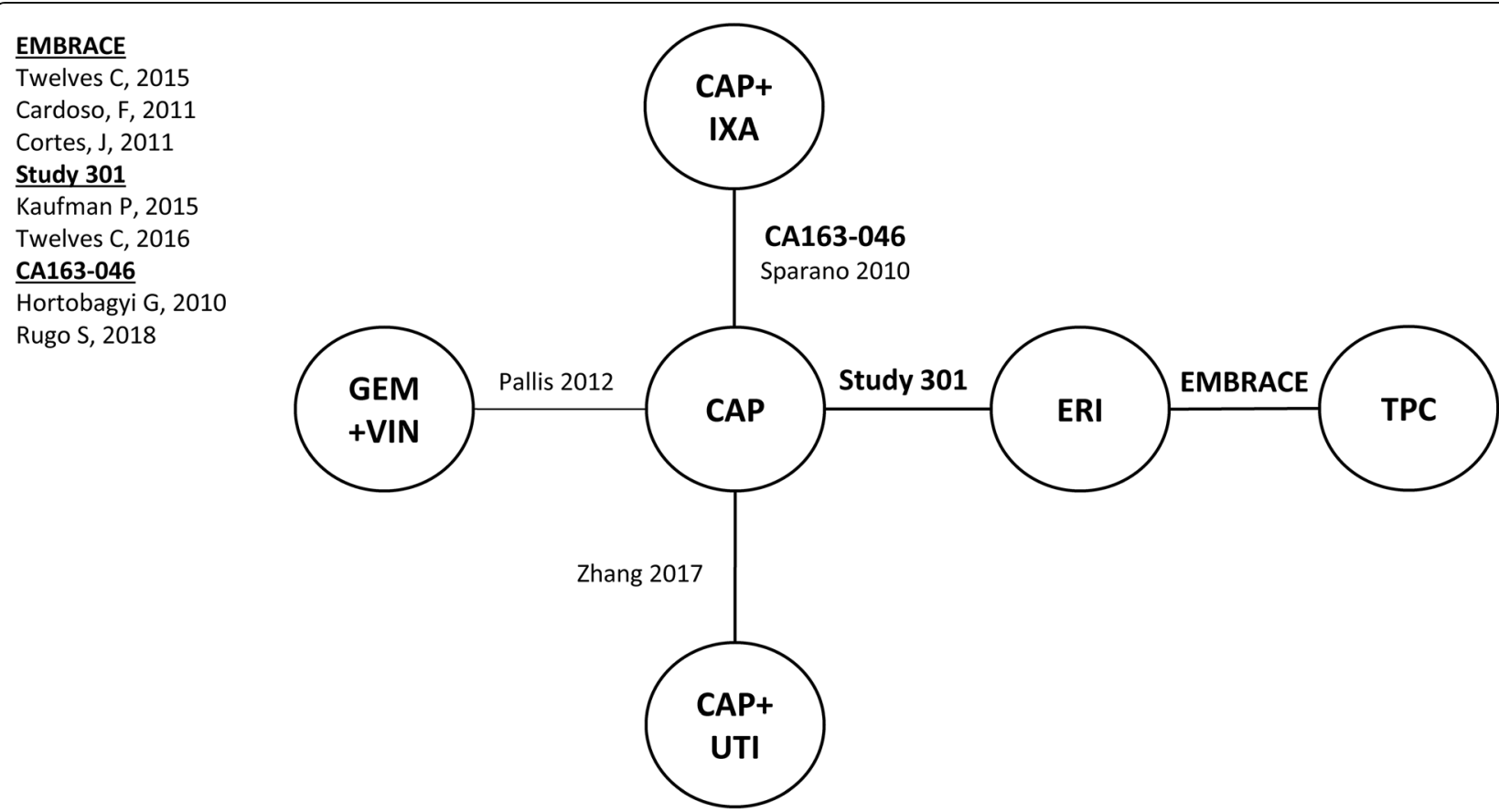

Fig. 4 Network Diagram: Progression-free Survival (Base-case Analysis). Abbreviations: CAP = capecitabine; $E R I=$ eribulin; GEM = gemcitabine; IXA = ixabepilone; TPC = treatment by physician's choice; UTI = utidelone; VIN = vinorelbine 


\section{Study 301 \\ Twelves C, 2016 \\ CA163-046}

Rugo S, 2018

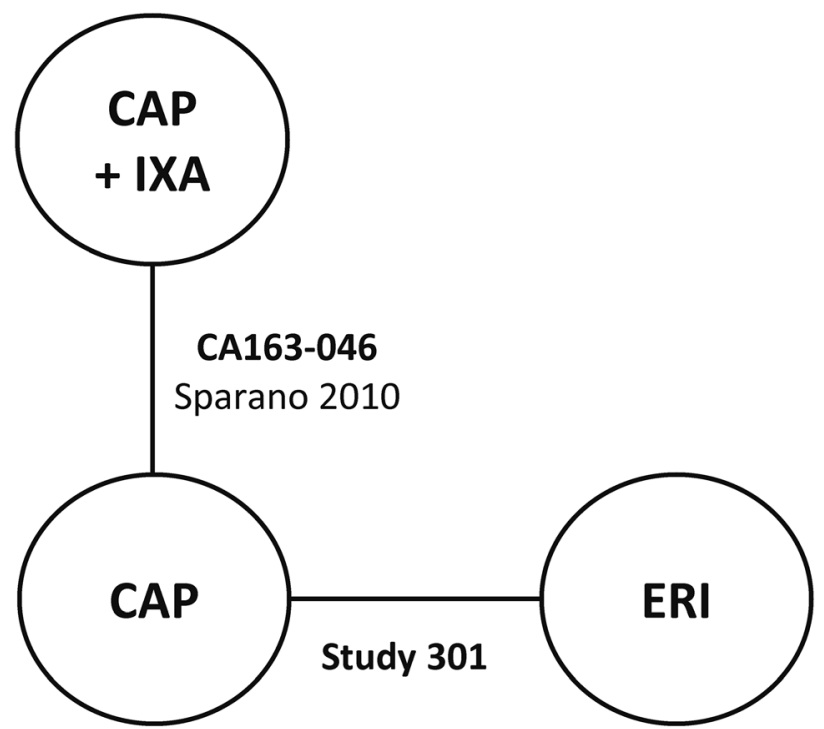

Fig. 5 Network Diagram: Progression-free Survival (TNBC Subgroup Analysis). Abbreviations: CAP = capecitabine; ERI = eribulin; IXA = ixabepilone; TNBC = triple negative breast cancer; TPC = treatment by physician's choice

talazoparib, bevacizumab, cetuximab, imatinib mesylate, onartuzumab, trastuzumab, sorafenib), eight trials did not connect to the networks for any outcomes of interest, and one trial used a study design not of interest (treatment switching). Subsequently, a total of seven RCTs were included in the NMA, as presented in the PRISMA diagram in Fig. 9.

\section{Treatment characteristics}

An overview of the study characteristics and treatments of the seven included trials is provided in Table 2. The frequency of treatments evaluated as monotherapy or combination therapy in the seven
RCTs included in the NMA were CAP (five studies), ERI (three studies), IXA (three studies), GEM (one study), UTI (one study), VIN (one study), and TPC (one study). Mechanisms of action of treatments evaluated included both antimicrotubule agents (ERI, IXA, UTI, VIN), antimetabolites (CAP, GEM), or therapeutic combinations of the two (e.g., GEM+VIN, $\mathrm{CAP}+\mathrm{UTI}$ ). Use of TPC involved administration of any single-agent chemotherapy, hormonal, or biological treatment approved for the treatment of cancer administered according to local practice, radiotherapy, or as symptomatic treatment alone. Four of the studies investigated combination strategies and



Fig. 6 Network Diagram: Progression-free Survival (HER2-negative Subgroup Analysis). Abbreviations: CAP = capecitabine; ERI = eribulin; $\mathrm{GEM}=$ gemcitabine; IXA = ixabepilone; TPC = treatment by physician's choice; VIN = vinorelbine 


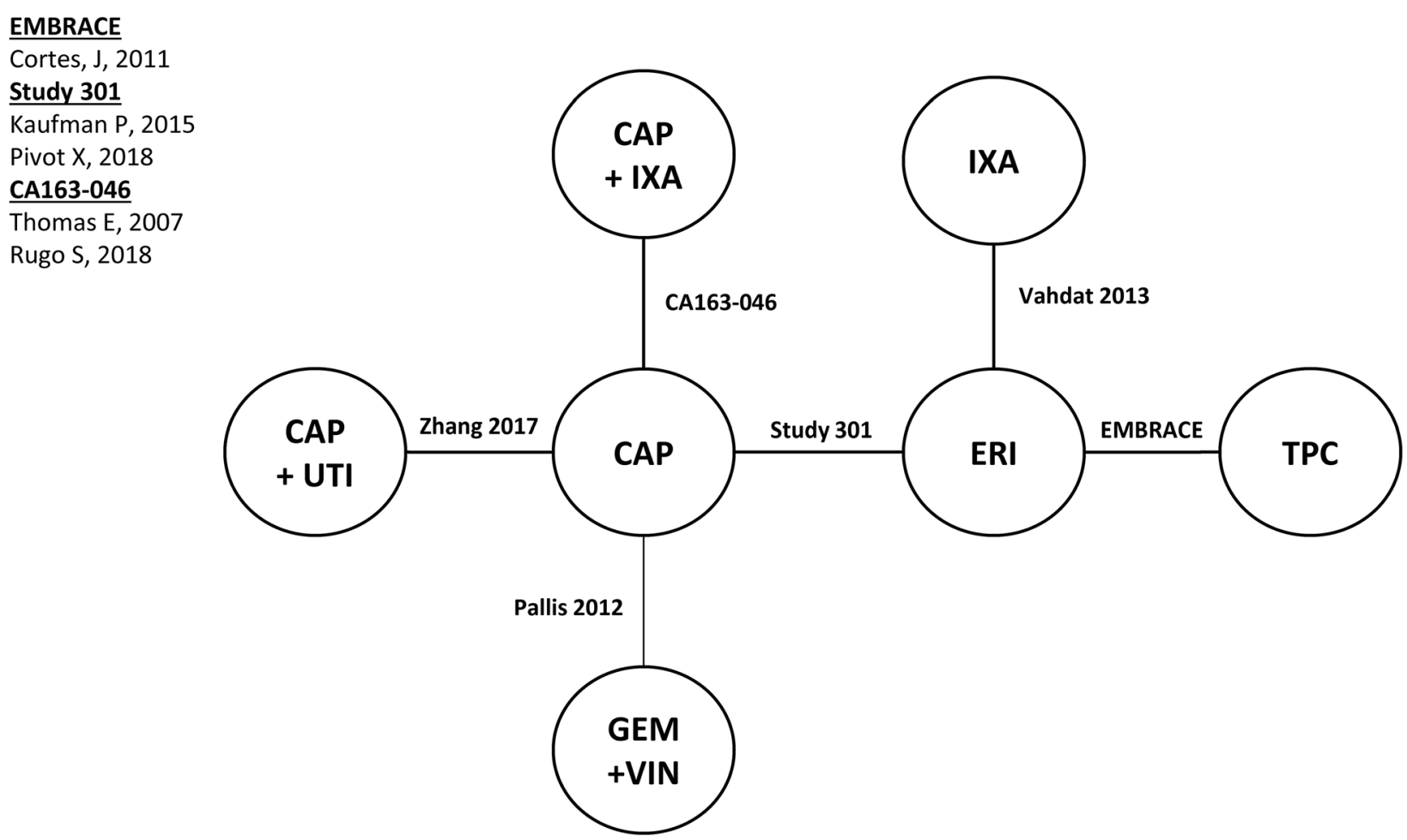

Fig. 7 Network Diagram: Discontinuation due to AEs (Base-case Analysis). Abbreviations: $A E=$ adverse event; $C A P=$ capecitabine; $E R I=e r i b u l i n$; GEM = gemcitabine; IXA = ixabepilone; TPC = treatment by physician's choice; UTI = utidelone; VIN = vinorelbine

three studies investigated use of monotherapies. Treatments evaluated in more than one RCT were each similar with respect to dosages, regimens, routes of administration, and cycle lengths.

\section{Patient characteristics}

A total of 4494 patients were included in the seven trials. Sample sizes ranged from 104 [20] to 1221 patients [24]. All patients had LABC or MBC and had received prior treatment with anthracyclines and taxanes. Two trials enrolled metastatic patients only [19,
25] and the remainder enrolled a mix of metastatic and locally advanced patients. Trial populations were generally similar with respect to known effect modifiers, including age, sex, type of prior therapy, and performance status (Eastern Cooperative Oncology Group [ECOG] and Karnofsky Performance Status [KPS]). Average age ranged from 50 [25] to 60 years [19]. Five trials provided baseline ECOG performance scores, and most patients had ECOG scores of 0 to 1 ; the percentage of patients with ECOG scores of 2 was low across the trials $(2 \%[12,25]$ to $8 \%[16])$.

\section{EMBRACE}

Cortes, J, 2011

Study 301

Kaufman P, 2015

Pivot X, 2018

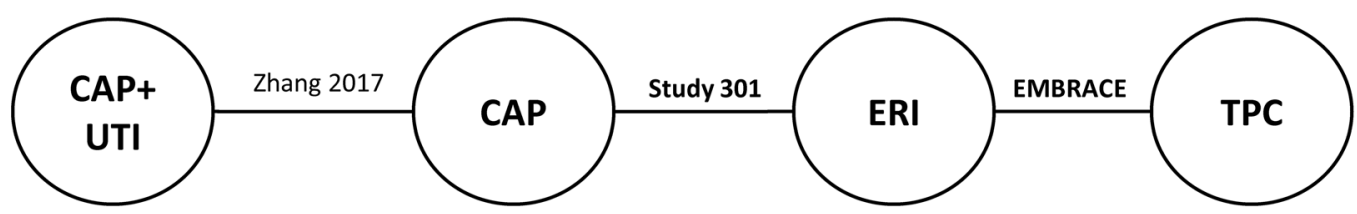

Fig. 8 Network Diagram: SAEs (Base-case Analysis). Abbreviations: CAP = capecitabine; $E R I=$ eribulin; SAE = serious adverse event; TPC = treatment by physician's choice; UTI = utidelone 


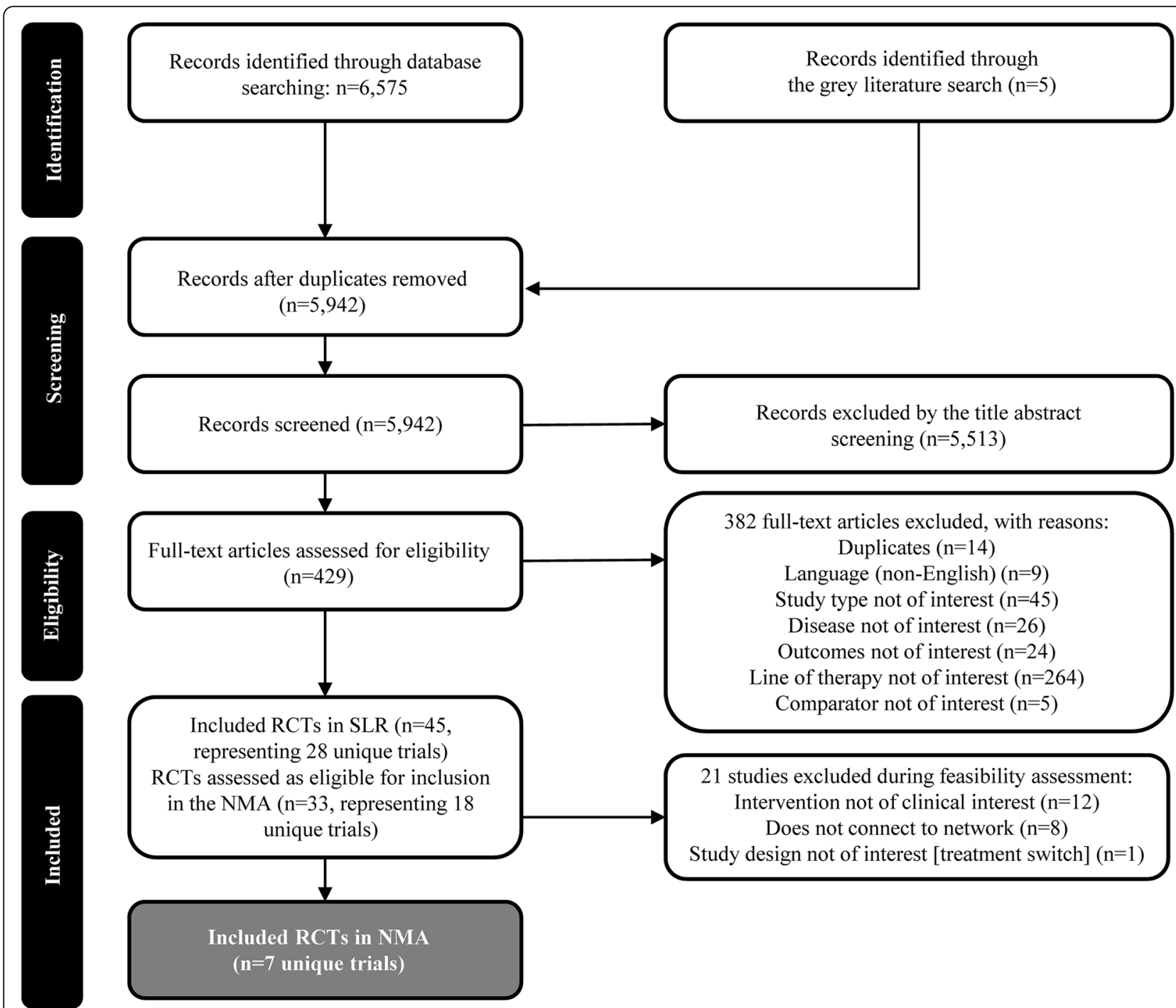

Fig. 9 PRISMA Flow Diagram of the SLR and NMA. Abbreviations: NMA = network meta-analysis; RCT = randomized controlled trial; $S L R=s y s t e m a t i c$ literature review

The remaining two trials measured baseline performance status according to KPS, and 65\% [24] and 70\% [22] of patients had scores of 90 to $100 \%$. Patient data for time from diagnosis to start of treatment was not available from five of the seven RCTs.

Across the seven included trials, heterogeneity was noted in the following potential effect modifiers: HER2 status, TNBC status, and number of prior treatments. A total of $16.1 \%$ of patients had HER2positive disease (11\% [20] to $26 \%$ [25] across trials) and $21.5 \%$ had TNBC (14\% [20] to 26\% [12] across trials). To explore the impact of this heterogeneity, subgroup analyses for TNBC and HER2-negative patients were conducted for the four RCTs that reported outcomes by TNBC status and the five RCTs that reported outcomes by HER2-negative status. All
RCTs enrolled mixed patient populations with $\geq 1$ prior ChT; $28 \%$ of trial populations (0\% [16] to $55 \%$ [19] per study) had received one prior treatment. The distribution of prior treatment across studies was: $\geq 1$ prior line (three trials $[19,20,22]$ ), 1-2 prior lines (one trial [24]), 1-3 prior lines (one trial [12]), 1-4 prior lines (one trial [25]), and 2-5 prior lines (one trial [16]). In the trial that enrolled mixed lines of therapy inclusive of first-line patients, only one patient had not received any prior chemotherapy $(<1 \%)$ [12]. While variability was observed for number of prior lines of therapy, NMA subgroup analysis of this characteristic was not feasible due to limited outcome stratification by line of therapy (e.g., two prior lines versus three or more prior lines as planned). 
Table 2 Overview of Study Characteristics of Trials Included in the NMA

\begin{tabular}{|c|c|c|c|c|c|}
\hline Trial & Brief Patient Description & $\begin{array}{l}\text { RCT } \\
\text { Design }\end{array}$ & Treatments & $\begin{array}{l}\mathrm{N} \\
\text { Randomized }\end{array}$ & Objectives \\
\hline $\begin{array}{l}\text { Study } 301 \\
\text { NCTO0337103 } \\
\text { Kaufman } \\
2015 \text { [12] } \\
\text { Twelves } \\
2016 \text { [13] } \\
\text { Cortes 2015 } \\
\text { [14] } \\
\text { Pivot 2018 } \\
\text { [15] }\end{array}$ & $\begin{array}{l}\text { Women with } \mathrm{MBC} \text { who had received prior } \\
\text { anthracycline- and taxane-based therapy }\end{array}$ & $\begin{array}{l}\text { Phase III } \\
\text { Open- } \\
\text { label }\end{array}$ & $\begin{array}{l}\text { 1) } E R I \\
\text { 2) } C A P\end{array}$ & 1102 & $\begin{array}{l}\text { To compare ERI with CAP in } \\
\text { patients with } \angle A B C \text { or } M B C \text {. }\end{array}$ \\
\hline $\begin{array}{l}\text { EMBRACE } \\
\text { NCT00388726 } \\
\text { Cortes } 2011 \\
\text { [16] } \\
\text { Twelves } \\
2015 \text { [17] } \\
\text { Cardoso } \\
2011 \text { [18] }\end{array}$ & $\begin{array}{l}\text { Women with heavily pre-treated (third line to fifth line) } \\
\text { locally recurrent or MBC }\end{array}$ & $\begin{array}{l}\text { Phase III } \\
\text { Open- } \\
\text { label }\end{array}$ & $\begin{array}{l}\text { 1) ERI } \\
\text { 2) TPC: } 25 \% \text { VIN, } 19 \% \text { GEM, } 18 \% \\
\text { CAP, } 15 \% \text { taxanes, } 10 \% \\
\text { anthracyclines, } 10 \% \text { other chemo, } \\
4 \% \text { hormonal therapy }\end{array}$ & 1102 & $\begin{array}{l}\text { To compare OS of women with } \\
\text { heavily pre-treated } \mathrm{MBC} \text { receiv- } \\
\text { ing ERI or real-life treatment } \\
\text { choices. }\end{array}$ \\
\hline $\begin{array}{l}\text { Pallis, } 2012 \\
\text { [19] } \\
\text { NCT00431106 }\end{array}$ & $\begin{array}{l}\text { Women with } \mathrm{MBC} \text {, pre-treated and/or resistant to } \\
\text { anthracyclines and taxanes }\end{array}$ & $\begin{array}{l}\text { Phase III } \\
\text { Blinding } \\
\text { NR }\end{array}$ & $\begin{array}{l}\text { 1) } C A P \\
\text { 2) } V I N+G E M\end{array}$ & 172 & $\begin{array}{l}\text { To demonstrate superiority of } \\
\text { combination treatment in terms } \\
\text { of PFS. }\end{array}$ \\
\hline $\begin{array}{l}\text { Vahdat, } 2013 \\
{[20]} \\
\text { NCT00879086 }\end{array}$ & $\begin{array}{l}\text { Women with locally recurrent or } \mathrm{MBC} \text { who had } \\
\text { received prior taxane therapy, at least one prior } \\
\text { cytotoxic chemotherapy for advanced disease, and } \\
\text { progressed during last anti-cancer treatment }\end{array}$ & $\begin{array}{l}\text { Phase II } \\
\text { Open- } \\
\text { label }\end{array}$ & $\begin{array}{l}\text { 1) } E R I \\
\text { 2) IXA }\end{array}$ & 104 & $\begin{array}{l}\text { To assess the incidence of } \\
\text { neuropathy. }\end{array}$ \\
\hline $\begin{array}{l}\text { CA163-046 } \\
\text { NCT00080301 } \\
\text { Thomas, } \\
2007 \text { [21] } \\
\text { Hortobagyi, } \\
2010 \text { [22] } \\
\text { Rugo 2018 } \\
\text { [23] }\end{array}$ & $\begin{array}{l}\text { Women with } \mathrm{LABC} \text { or } \mathrm{MBC} \text {, pre-treated with or resist- } \\
\text { ant to anthracyclines and taxanes }\end{array}$ & $\begin{array}{l}\text { Phase III } \\
\text { Open- } \\
\text { label }\end{array}$ & $\begin{array}{l}\text { 1) } I X A+C A P \\
\text { 2) } C A P\end{array}$ & 752 & $\begin{array}{l}\text { To describe the results of OS } \\
\text { from the CA163-046 phase III } \\
\text { study. }\end{array}$ \\
\hline $\begin{array}{l}\text { CA163-048 } \\
\text { NCT00082433 } \\
\text { Sparano } \\
2010[24] \\
\text { Rugo 2018 } \\
{[23]}\end{array}$ & $\begin{array}{l}\text { Women previously treated with an anthracycline- and } \\
\text { taxane-containing regimen }\end{array}$ & $\begin{array}{l}\text { Phase III } \\
\text { Open- } \\
\text { label }\end{array}$ & $\begin{array}{l}\text { 1) } I X A+C A P \\
\text { 2) } C A P\end{array}$ & 1221 & $\begin{array}{l}\text { To assess whether the } \\
\text { combination improved survival } \\
\text { compared with CAP } \\
\text { monotherapy. }\end{array}$ \\
\hline $\begin{array}{l}\text { Zhang } 2017 \\
\text { [25] } \\
\text { NCT02253459 }\end{array}$ & $\begin{array}{l}\text { Female patients with } \mathrm{MBC} \text { refractory to anthracycline } \\
\text { and taxane }\end{array}$ & $\begin{array}{l}\text { Phase III } \\
\text { Open- } \\
\text { label }\end{array}$ & $\begin{array}{l}\text { 1) UTI + CAP } \\
\text { 2) CAP }\end{array}$ & 405 & $\begin{array}{l}\text { To compare the efficacy and } \\
\text { safety of UTI + CAP vs. CAP } \\
\text { alone in patients with MBC. }\end{array}$ \\
\hline
\end{tabular}

Abbreviations: CAP CApecitabinek, ERI Eribulin, GEM Gemcitibine, HER2 Human epidermal growth factor receptor 2, IXA Ixabepilone, LABC Locally advanced breast cancer, MBC Metastatic breast cancer, NR Not reported, OS Overall survival, PFS Progression-free survival, RCT Randomized controlled trial, TPC Treatment by physician's choice, UTI Utidelone, VIN Vinorelbine






ERI vs CAP
ERI vs TPC

\section{Outcome assessments}

Of the seven trials, six reported OS, six reported PFS, six reported discontinuation due to AEs, and three reported SAEs. All trials provided definitions for the primary outcome assessments (OS and PFS), and no differences were observed across the trials. For safety outcomes, all studies assessed adverse events (AEs) using the National Cancer Institute Common Terminology Criteria for Adverse Events (CTCAE version 3 or 4), except for one study which did not report a definition.

\section{Risk-of-Bias assessments}

Most RCTs were assessed as having a low risk of bias (Additional file 2); however, some concerns were noted for one trial, in which differences in baseline performance status were noted in addition to its open-label design [22].

\section{Network meta-analysis}

Eight sets of analyses are presented, including two basecase analyses for OS and PFS, two TNBC subgroup analyses for OS and PFS, two HR-positive/HER2-negative subgroup analyses for OS and PFS, and two safety analyses.

\section{Overall survival}

In the base-case analysis, ERI-treated patients had statistically longer OS compared with those treated with TPC (HR: 0.81; 95\% CrI: 0.66-0.99) or GEM+VIN (HR: 0.62 ; 95\% CrI: 0.42-0.90) (Fig. 10). No other base-case comparisons were statistically different. In the TNBC subgroup, ERI had statistically longer OS compared with CAP (HR: 0.70; 95\% CrI: 0.54-0.90) (Fig. 11). Point estimates for OS across the remaining TNBC subgroup comparisons favored ERI; however, none of these comparisons were statistically different. In the HR-positive/HER2-negative subgroup, ERItreated patients also had statistically longer OS than those treated with CAP (HR: 0.84; 95\% CrI: 0.710.98). Point estimates for OS in HR-positive/HER2negative subgroups favored ERI for all remaining comparisons; however, similar to the TNBC subgroup

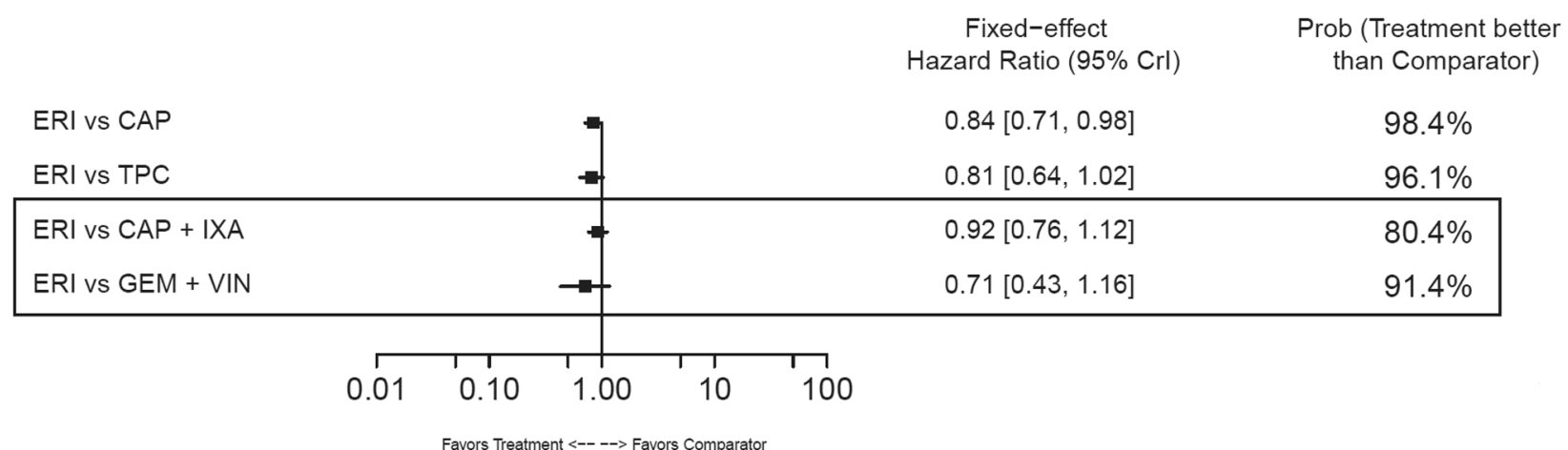

Fig. 12 Forest Plot of Overall Survival Treatment Comparison: HER2- Subgroup Analysis. Estimates derived only from indirect comparisons shown in black box. Included references: Study 301 (Twelves 2016), EMBRACE (Cortes 2011), CA163-046 (Hortobagyi 2010; Rugo 2018), Sparano 2010, Pallis 2012. Abbreviations: CAP = capecitabine; $\mathrm{Crl}$ = credible interval; $\mathrm{ERI}=$ eribulin; $\mathrm{GEM}=$ gemcitabine; HER2 = human epidermal growth factor receptor 2; IXA = ixabepilone; TPC = treatment by physician's choice; VIN = vinorelbine 


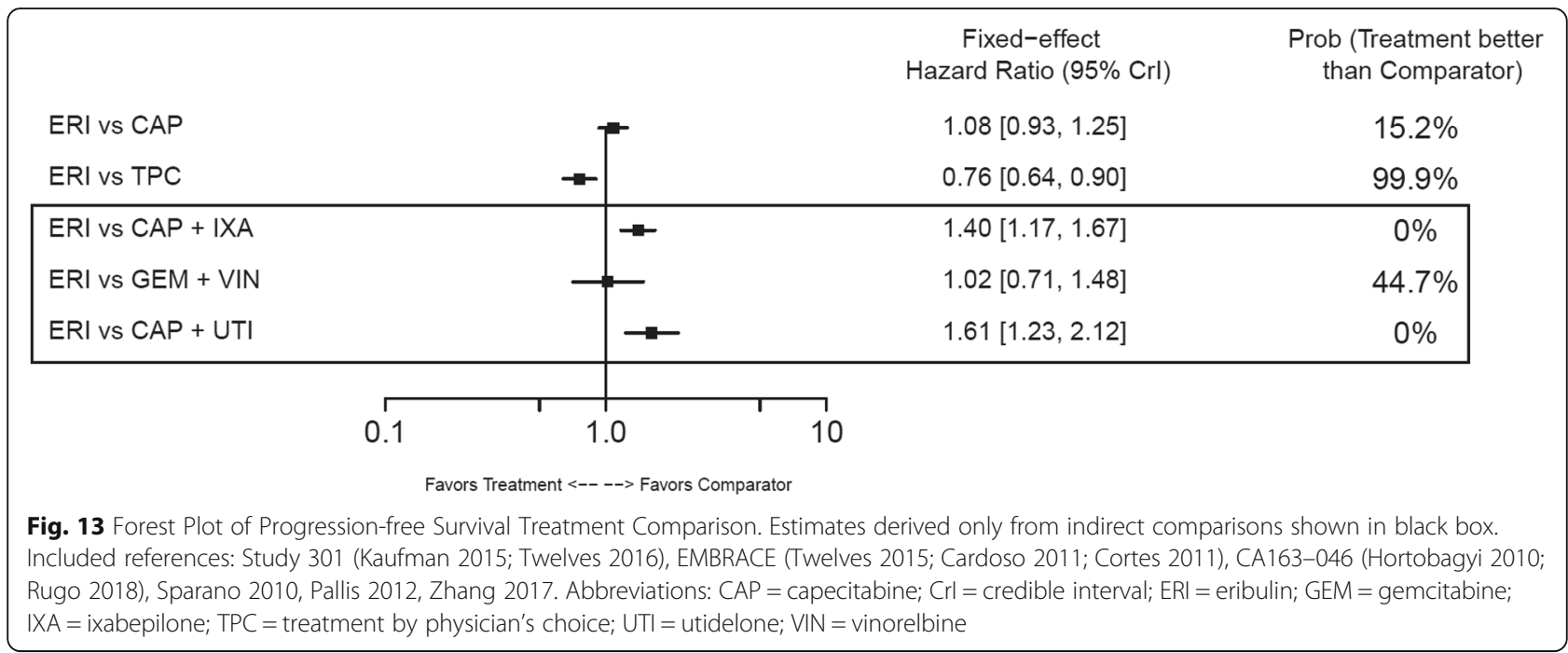

results, these comparisons were not statistically different (Fig. 12).

\section{Progression-free survival}

In the base-case analysis, ERI was associated with a significantly longer PFS compared with TPC (HR: 0.76; 95\% CrI: 0.64-0.90) and a significantly shorter PFS versus CAP+IXA (HR: 1.40; 95\% CrI: 1.17-1.67) and CAP+UTI (HR:1.61; 95\% CrI: 1.23-2.12) (Fig. 13). No statistical differences for ERI versus comparators were observed in the TNBC subgroup (Fig. 14), whose network had only two comparisons. In the HR-positive/HER2-negative subgroup, which comprised three treatment comparisons, patients treated with CAP+IXA had statistically longer PFS than those treated with ERI (HR: 1.29; 95\% CrI:1.05-1.58) (Fig. 15).

\section{Safety}

In safety outcome analyses, there was a trend toward ERI reducing treatment discontinuation due to AEs across all comparators, with statistical advantages compared with CAP+IXA (HR: 0.25; 95\% CrI: 0.130.47), CAP+UTI (HR: 0.33; 95\% CrI: 0.11-0.87), and IXA (HR: 0.27; 95\% CrI: 0.09-0.75). No statistical differences between the other comparisons were observed (Fig. 16). No statistical differences were found between ERI and any comparator for SAEs (Fig. 17).

\section{Discussion}

This SLR and NMA estimated the relative efficacy and safety of ERI as a $2 \mathrm{~L}+$ treatment for $\mathrm{LABC} / \mathrm{MBC}$ versus other ChTs in the overall population and in subgroups of TNBC and HR-positive/HER2-negative patients. The SLR and NMA were conducted in accordance with published guidelines and based on well-established Bayesian methodology $[11,26]$. Three of the seven RCTs included in the NMA directly compared ERI to other active treatments [12-14, 16-18]. Using Bayesian NMA, it was possible to pool and indirectly compare RCT evidence on treatments for which no head-to-head trials were available. For example, outcomes from four trials providing data for CAP + IXA (two trials), CAP + UTI, and GEM

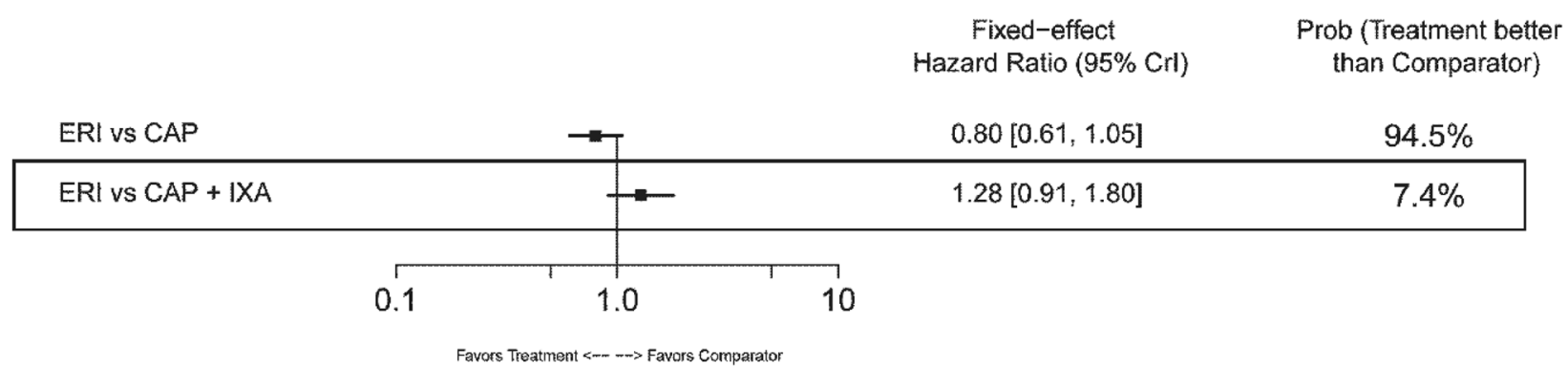

Fig. 14 Forest Plot of Progression-free Survival Treatment Comparison: TNBC Subgroup Analysis. Estimates derived only from indirect comparisons shown in black box. Included references: Study 301 (Kaufman 2015), CA163-046 (Rugo 2018), Sparano 2010. Abbreviations: CAP = capecitabine; $\mathrm{Cr}$ = credible interval; $\mathrm{ERI}=$ eribulin; $\mid \mathrm{XA}=$ ixabepilone; TNBC = triple negative breast cancer 


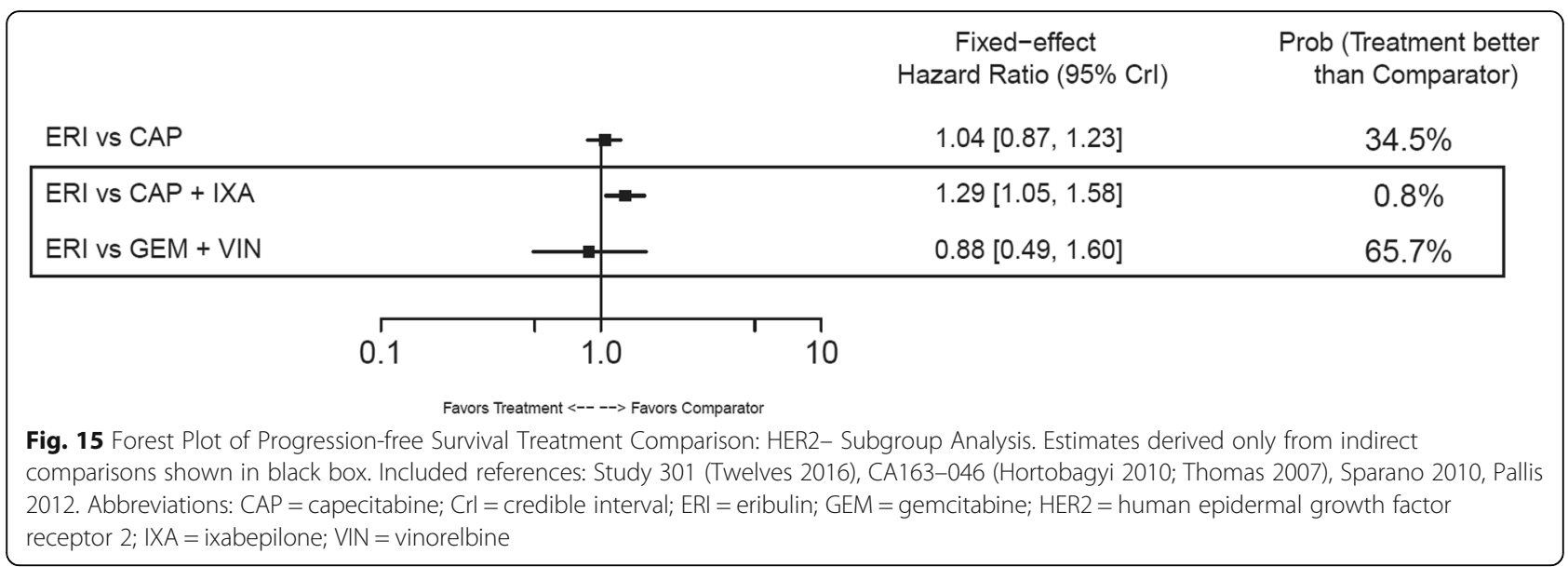

+ VIN were indirectly compared to ERI for OS and PFS base-case analyses.

While baseline patient characteristics across the seven RCTs in the NMA were generally similar for most patient characteristics such as age and performance status, variability was noted for known effect modifiers of TNBC status, HR-positive/HER2-negative status, and number of lines of therapy. Analyses of these subgroups was warranted to explore differences in treatment effect in these specific populations versus the broader overall population; however, not all trials provided outcome data stratified by TNBC status or by HR-positive/HER2-negative status. Differences across the included trials were also noted for number of prior lines of therapy. Given heterogeneity of treatment effect originating from number of prior lines of therapy may exist, the NMA sought to examine the differences, but limited OS and PFS data stratified by line of therapy across the included trials prevented this analysis. The inability to conduct these analyses is a limitation of the NMA, as the number of prior lines of therapy is a potential effect modifier in $\mathrm{LABC} / \mathrm{MBC}$ and stratification by line of therapy has been integral to the methodology of existing NMAs in the disease area $[27,28]$.

In the base-case network, the NMA showed statistically significant prolongation of OS for ERI-treated patients compared to TPC- or GEM+VIN-treated patients. The NMA also showed a trend for longer OS in CAP+UTItreated patients over ERI-treated patients, but this difference was not statistically significant. In TNBC and HRpositive/HER2-negative subgroups, the NMA showed statistically significant OS benefit for treatment with ERI versus CAP. Similar to the OS results, significantly longer PFS was observed in ERI-treated patients compared with TPC; however, in the base-case PFS network, the NMA found that treatment with CAP+UTI or CAP+IXA had significantly prolonged PFS compared to ERI. Further, in the HR-positive/HER2-negative subpopulation, CAP+IXA also had longer PFS compared with ERI.

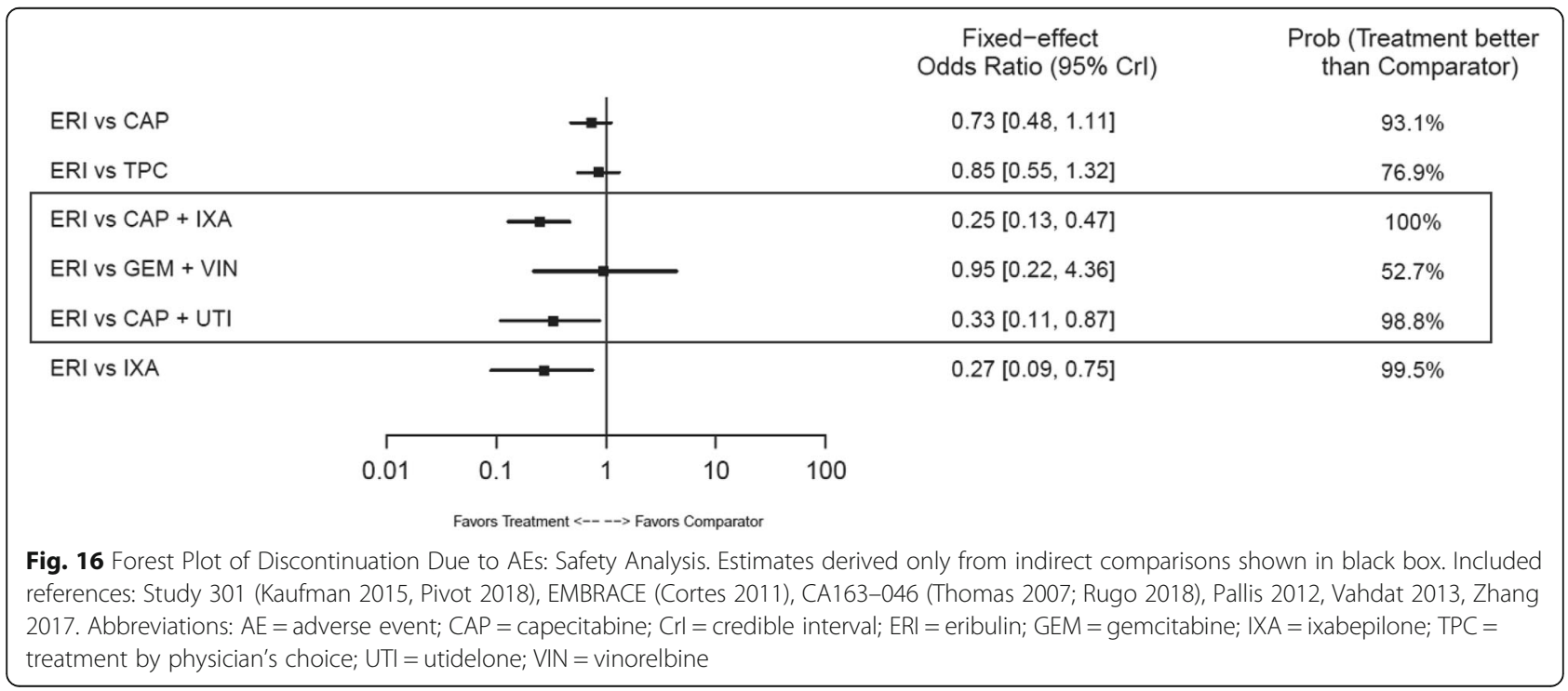




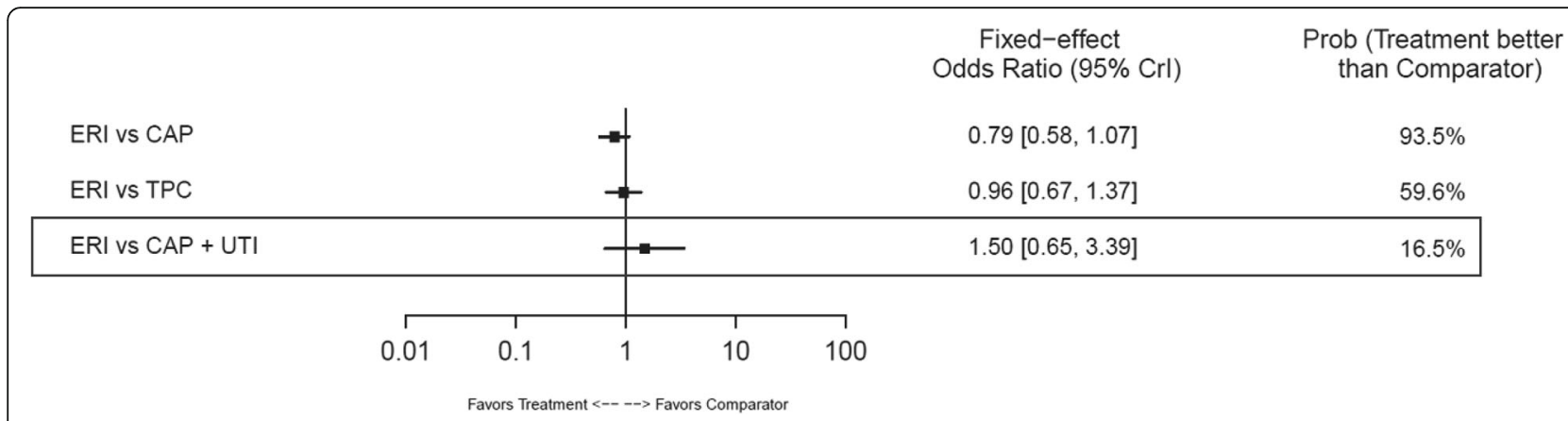

Fig. 17 Forest Plot of SAEs: Safety Analysis. Estimates derived only from indirect comparisons shown in black box. Included references: Study 301

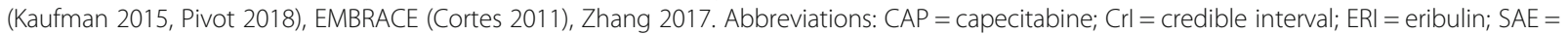
serious adverse event; TPC = treatment by physician's choice; UTI = utidelone

Between the execution of the searches on 22 March 2019 and the drafting of this manuscript, an additional relevant publication, Yuan et al. 2019 [29], has been identified that would contribute to the NMA networks. Since this trial was published outside of the existing search dates, it was not eligible for inclusion in the current analysis; however, a systematic update to the SLR was conducted on 8 January 2021 that confirmed the publication's eligibility for inclusion, and an updated feasibility assessment and NMA are in progress. Yuan et al. 2019 investigates a head-to-head comparison of two key comparators-ERI and VIN. The inclusion of a connection to VIN monotherapy in the analysis would expand the existing base-case network by opening additional indirect comparisons to other eligible comparators including: docetaxel [30], GEM + docetaxel [31], CAP + docetaxel [32], paclitaxel [33], and nab-paclitaxel [34, 35].

The most important limitation of this NMA was the lack of data to control for population-level differences in determinants of response to treatment. For example, the duration of response to prior lines of therapy and quality of prior response are known to be important effect modifiers in $\mathrm{LABC} / \mathrm{MBC}$, along with line of therapy, as noted earlier. However, these analyses were ultimately not possible due to lack of stratification of the published RCT data by these factors. This NMA was also constrained by the small number of treatment comparisons available for outcomes of interest both for the base-case and for subgroups. A larger data pool may have allowed for indirect comparisons of ERI with other ChTs of interest and may have helped reduced CrIs for those comparisons which were possible, but it should be noted that additional RCTs would also potentially introduce additional heterogeneity into the networks. The strengths of this review were first its methodology, which was systematic, reproducible, and adherent to PRISMA guidelines and second, its thorough comparison and assessment of the evidence base for inclusion, with relevant scenario analyses conducted when permitted by available data.

\section{Conclusion}

This NMA of available RCTs suggests that ERI may provide a favorable OS benefit in overall LABC/MBC populations and TNBC subgroups compared to standard treatments. Specifically, the NMA suggests that ERI provides a statistically significant OS benefit compared with TPC and GEM+VIN in $2 \mathrm{~L}+$ treatment of patients with LABC/MBC and compared with CAP in TNBC and HRpositive/HER2-negative subgroups. ERI shows significantly lower rates of discontinuation due to AEs than CAP+IXA, CAP+UTI, and IXA. These NMA findings further support the clinical value of treatment with ERI in $\mathrm{LABC} / \mathrm{MBC}$.

\section{Abbreviations}

$2 \mathrm{~L}+$ : Second- or later-line; $3 \mathrm{L+}$ : Third- or later-line.; AE: Adverse event; ASCO: American Society of Clinical Oncology; CAP: Capecitabine;

ChT: Chemotherapy; Crl: Credible interval; CTCAE: Common Terminology Criteria for Adverse Events; DOC: Docetaxel; ECOG: Eastern Cooperative Oncology Group; EMA: European Medicines Agency; ERI: Eribulin mesylate; ESMA: European Society of Medical Oncology; EU: European Union; FDA: Food and Drug Administration; GEM: Gemcitabine; HER2: Human epidermal growth factor receptor 2; HR: Hazard ratio; HR: Hormone receptor; ISPOR: International Society for Pharmacoeconomics and Outcomes Research; IXA: Ixabepilone; KPS: Karnofsky Performance Status; LABC: Locally advanced breast cancer; MBC: Metastatic breast cancer; NICE: National Institute for Health and Care Excellence; NMA: Network meta-analysis; OR: Odds ratio; OS: Overall survival; PFS: Progression-free survival; PICOS: Population, interventions, comparisons, outcomes, and study design; PRISMA: Preferred Reporting Items for Systematic Reviews and MetaAnalyses; RCT: Randomized controlled trial; SAE: Serious adverse event; SLR: Systematic literature review; TDAE: Treatment discontinuation due to adverse events; TNBC: Triple negative breast cancer; TPC: Treatment by physician's choice; US: United States; UTI: Utidelone; VIN: Vinorelbine

\section{Supplementary Information}

The online version contains supplementary material available at https://doi. org/10.1186/s12885-021-08446-8.

Additional file 1. Systematic Literature Review Search Strategies. Tables containing the terms and yields for searches conducted in Embase, MEDL INE, and Cochrane library from 1 January 2007 to 22 March 2019.

Additional file 2. Risk of Bias Assessment Results. Figure depicting the risk of bias assessment results of individual included studies assessed using the Centre for Reviews and Dissemination tool. 


\section{Acknowledgements}

We would like to thank Michael Grossi and Sean Smith of Evidera for their valuable contributions in providing medical writing, editorial, and formatting support for this manuscript.

\section{Authors' contributions}

All named authors (QZ, RH, BN, KM, YS, IC, MB, AK) meet the International Committee of Medical Journal Editors (ICMJE) criteria for authorship for this manuscript, take responsibility for the integrity of the work as a whole, and have given final approval to the version to be published. QZ, RH, YS, MB, and AK made substantial contributions to the conception and design of the protocol. $\mathrm{RH}, \mathrm{KM}$, and $\mathrm{AK}$ conducted the systematic literature review. $\mathrm{BN}, \mathrm{RH}$ $\mathrm{KM}$, and $\mathrm{AK}$ conducted the network meta-analysis. $\mathrm{RH}, \mathrm{AK}, \mathrm{MB}, \mathrm{QZ}$, and IC drafted the work and substantially revised it.

\section{Funding}

Eisai Inc. provided the funding for the study and for the manuscript. Employees of the funding body, Eisai Inc., took part in the design of the study, interpretation of data, and the writing of the manuscript.

\section{Availability of data and materials}

Not applicable.

\section{Declarations}

Ethics approval and consent to participate

Not applicable.

\section{Consent for publication}

Not applicable.

\section{Competing interests}

QZ is a salaried employee of Eisai Inc. YS was a salaried employee of Eisai Inc. at the time of the study. $\mathrm{RH}, \mathrm{BN}, \mathrm{KM}, \mathrm{MB}$, and $\mathrm{AK}$ are salaried employees of Evidera, which received funding from Eisai Inc. to conduct the study and develop the manuscript; they are not allowed to accept remuneration from any clients for their services. IC acted as a paid consultant to Eisai Inc. for this work.

\section{Author details}

${ }^{1}$ Global Value \& Access, Eisai Inc, Woodcliff Lake, NJ, USA. ${ }^{2}$ Evidence Synthesis, Modeling \& Communication, Evidera, San Francisco, CA, USA ${ }^{3}$ Evidence Synthesis, Modeling \& Communication, Evidera, Montreal, QC, Canada. ${ }^{4}$ Evidence Synthesis, Modeling \& Communication, Evidera, Waltham, MA, USA. ${ }^{5}$ Global Value \& Access, Eisai Inc., Woodcliff Lake, NJ, USA. ${ }^{6}$ Faculté de pharmacie, University of Montreal, Montreal, QC, Canada.

\section{Received: 10 November 2020 Accepted: 4 June 2021}

Published online: 30 June 2021

\section{References}

1. National Cancer Institute, Surveillance, Epidemiology, and End Results Program (SEER). Cancer Stat Facts: Female Breast Cancer [Available from: https:// seer.cancer.gov/statfacts/html/breast.html.

2. Tryfonidis K, Senkus E, Cardoso MJ, Cardoso F. Management of locally advanced breast cancer-perspectives and future directions. Nat Rev Clin Oncol. 2015;12(3):147-62. https://doi.org/10.1038/nrclinonc.2015.13.

3. Roche H, Vahdat LT. Treatment of metastatic breast cancer: second line and beyond. Ann Oncol. 2011;22(5):1000-10. https://doi.org/10.1093/annonc/ mdq429.

4. European Medicines Agency (EMA). Halaven (eribulin): summary of the European public assessment report (EPAR) for Halaven. Last update: Feb 2 2018. 2011; http://www.ema.europa.eu/ema/index.jsp?curl=pages/ medicines/human/medicines/002084/human_med_001427.jsp\&mid= WC0b01ac058001d124. Accessed June 2018

5. Eisai Inc. HALAVEN ${ }^{\circledast}$ (eribulin mesylate) injection, for intravenous use. Ful Prescribing information. Initial U.S. Approval: 2010. Revised: October 2016. 2016; https://www.halaven.com/-/media/Files/Halaven/HALAVEN-FullPrescribing-Information.pdf. Accessed June 2018.

6. Jain S, Cigler T. Eribulin mesylate in the treatment of metastatic breast cancer. Biologics. 2012;6:21-9. https://doi.org/10.2147/BTT.S19811.
7. Hutton B, Salanti G, Caldwell DM, Chaimani A, Schmid CH, Cameron C, et al. The PRISMA extension statement for reporting of systematic reviews incorporating network meta-analyses of health care interventions: checklist and explanations. Ann Intern Med. 2015;162(11):777-84. https://doi.org/10. 7326/M14-2385

8. Liberati A, Altman DG, Tetzlaff J, Mulrow C, Gøtzsche PC, loannidis JP, et al. The PRISMA statement for reporting systematic reviews and meta-analyses of studies that evaluate health care interventions: explanation and elaboration. PLoS Med. 2009;6(7):e1000100. https://doi.org/10.1371/journal. pmed. 1000100 .

9. National Institute for Health and Care Excellence (NICE). Guide to the methods of technology appraisal 2013. Process and methods (PMG9) [Available from: https://www.nice.org.uk/process/pmg9/chapter/foreword.

10. Caldwell DM, Ades AE, Higgins JP. Simultaneous comparison of multiple treatments: combining direct and indirect evidence. BMJ. 2005;331(7521): 897-900. https://doi.org/10.1136/bmj.331.7521.897.

11. Lu G, Ades AE. Combination of direct and indirect evidence in mixed treatment comparisons. Stat Med. 2004;23(20):3105-24. https://doi.org/10.1 002/sim.1875.

12. Kaufman PA, Awada A, Twelves C, Yelle L, Perez EA, Velikova G, et al. Phase III open-label randomized study of eribulin mesylate versus capecitabine in patients with locally advanced or metastatic breast cancer previously treated with an anthracycline and a taxane. J Clin Oncol. 2015;33(6):594601. https://doi.org/10.1200/JCO.2013.52.4892

13. Twelves C, Awada A, Cortes J, Yelle L, Velikova G, Olivo MS, et al. Subgroup analyses from a phase 3, open-label, randomized study of eribulin mesylate versus capecitabine in pretreated patients with advanced or metastatic breast cancer. Breast Cancer (Auckl). 2016:10:77-84.

14. Cortes J, Hudgens S, Twelves C, Perez EA, Awada A, Yelle L, et al. Healthrelated quality of life in patients with locally advanced or metastatic breast cancer treated with eribulin mesylate or capecitabine in an open-label randomized phase 3 trial. Breast Cancer Res Treat. 2015;154(3):509-20. https://doi.org/10.1007/s10549-015-3633-7.

15. Pivot X, Im SA, Guo M, Marmé F. Subgroup analysis of patients with HER2negative metastatic breast cancer in the second-line setting from a phase 3, open-label, randomized study of eribulin mesilate versus capecitabine. Breast Cancer. 2018;25(3):370-4. https://doi.org/10.1007/s12282-017-0826-4.

16. Cortes J, O'Shaughnessy J, Loesch D, Blum JL, Vahdat LT, Petrakova K, et al. Eribulin monotherapy versus treatment of physician's choice in patients with metastatic breast cancer (EMBRACE): a phase 3 open-label randomised study. Lancet. 2011;377(9769):914-23. https://doi.org/10.1016/50140-6736(11)60070-6.

17. Twelves C, Cortes J, Kaufman P, Yelle L, Awada A, Binder T, et al. "New" metastases are associated with a poorer prognosis than growth of preexisting metastases in patients with metastatic breast cancer treated with chemotherapy. Breast Cancer Res. 2015;17(150). https://doi.org/10.11 86/s13058-015-0657-1

18. Cardoso F, Twelves C, Vahdat L, Dutcus C, Seegobin S, Wanders J, et al. Eribulin mesylate EMBRACE study - survival analysis excluding patients rechallenged with therapies of the same class. Eur J Cancer. 2011;47(S332): S331-2. https://doi.org/10.1016/S0959-8049(11)71448-4.

19. Pallis AG, Boukovinas I, Ardavanis A, Varthalitis I, Malamos N, Georgoulias V, et al. A multicenter randomized phase III trial of vinorelbine/gemcitabine doublet versus capecitabine monotherapy in anthracycline- and taxanepretreated women with metastatic breast cancer. Ann Oncol. 2012;23(5): 1164-9. https://doi.org/10.1093/annonc/mdr405.

20. Vahdat LT, Garcia AA, Vogel C, Pellegrino C, Lindquist DL, lannotti N, et al. Eribulin mesylate versus ixabepilone in patients with metastatic breast cancer: a randomized phase II study comparing the incidence of peripheral neuropathy. Breast Cancer Res Treat. 2013;140(2):341-51. https://doi.org/10.1 007/s10549-013-2574-2.

21. Thomas ES, Gomez HL, Li RK, Chung HC, Fein LE, Chan VF, et al. Ixabepilone plus capecitabine for metastatic breast cancer progressing after anthracycline and taxane treatment. J Clin Oncol. 2007;25(33):5210-7. https://doi.org/10.1200/JCO.2007.12.6557.

22. Hortobagyi GN, Gomez HL, Li RK, Chung HC, Fein LE, Chan VF, et al. Analysis of overall survival from a phase III study of ixabepilone plus capecitabine versus capecitabine in patients with $\mathrm{MBC}$ resistant to anthracyclines and taxanes. Breast Cancer Res Treat. 2010;122(2):409-18. https://doi.org/10.1 007/s10549-010-0901-4.

23. Rugo HS, Roche H, Thomas E, Chung HC, Lerzo GL, Vasyutin I, et al. Efficacy and safety of ixabepilone and capecitabine in patients with advanced triple- 
negative breast cancer: a pooled analysis from two large phase III, Randomized Clinical Trials. Clin Breast Cancer. 2018;18(6):489-97. https://doi. org/10.1016/j.clbc.2018.07.024.

24. Sparano JA, Vrdoljak E, Rixe O, Xu B, Manikhas A, Medina C, et al. Randomized phase III trial of ixabepilone plus capecitabine versus capecitabine in patients with metastatic breast cancer previously treated with an anthracycline and a taxane. J Clin Oncol. 2010;28(20):3256-63. https://doi.org/10.1200/JCO.2009.24.4244.

25. Zhang P, Sun T, Zhang Q, Yuan Z, Jiang Z, Wang XJ, et al. Utidelone plus capecitabine versus capecitabine alone for heavily pretreated metastatic breast cancer refractory to anthracyclines and taxanes: a multicentre, openlabel, superiority, phase 3, randomised controlled trial. Lancet Oncol. 2017; 18(3):371-83. https://doi.org/10.1016/S1470-2045(17)30088-8.

26. Sutton AJ, Abrams KR. Bayesian methods in meta-analysis and evidence synthesis. Stat Methods Med Res. 2001;10(4):277-303. https://doi.org/10.11 77/096228020101000404

27. Cameron C, Fireman B, Hutton B, Clifford T, Coyle D, Wells G, et al. Network meta-analysis incorporating randomized controlled trials and nonrandomized comparative cohort studies for assessing the safety and effectiveness of medical treatments: challenges and opportunities. Syst Rev. 2015;4(1):147. https://doi.org/10.1186/s13643-015-0133-0.

28. Wilson FR, Varu A, Mitra D, Cameron C, lyer S. Systematic review and network meta-analysis comparing palbociclib with chemotherapy agents for the treatment of postmenopausal women with HR-positive and HER2negative advanced/metastatic breast cancer. Breast Cancer Res Treat. 2017; 166(1):167-77. https://doi.org/10.1007/s10549-017-4404-4.

29. Yuan P, Hu X, Sun T, Li W, Zhang Q, Cui S, et al. Eribulin mesilate versus vinorelbine in women with locally recurrent or metastatic breast cancer: a randomised clinical trial. Eur J Cancer. 2019;112:57-65. https://doi.org/10.101 6/j.ejca.2019.02.002.

30. Palmieri C, Alifrangis C, Shipway D, Tat T, Watson V, Mackie D, et al. A randomized feasibility study of docetaxel versus vinorelbine in advanced breast cancer. Oncologist. 2012;17(11):1429-e47. https://doi.org/10.1634/ theoncologist.2012-0161.

31. Papadimitriou CA, Kalofonos H, Zagouri F, Papakostas P, Bozas G, Makatsoris $T$, et al. Weekly docetaxel with or without gemcitabine as second-line chemotherapy in paclitaxel-pretreated patients with metastatic breast cancer: a randomized phase II study conducted by the Hellenic cooperative oncology group. Oncology. 2009;77(3-4):212-6. https://doi.org/1 $0.1159 / 000236021$

32. Chan S, Romieu G, Huober J, Delozier T, Tubiana-Hulin M, Schneeweiss A, et al. Phase III study of gemcitabine plus docetaxel compared with capecitabine plus docetaxel for anthracycline-pretreated patients with metastatic breast cancer. J Clin Oncol. 2009;27(11):1753-60. https://doi.org/1 $0.1200 / J C O .2007 .15 .8485$

33. Aapro M, Ruiz-Borrego M, Hegg R, Kukielka-Budny B, Morales S, Cinieri S, et al. Randomized phase II study evaluating weekly oral vinorelbine versus weekly paclitaxel in estrogen receptor-positive, HER2-negative patients with advanced breast cancer (NorBreast-231 trial). Breast. 2019;45:7-14. https:// doi.org/10.1016/j.breast.2019.01.009

34. Cortes J, Perez-Garcia J, Whiting S, Wan Y, Solem C, Tai MH, et al. Qualityadjusted survival with nab-paclitaxel versus standard paclitaxel in metastatic breast cancer: a Q-TWiST analysis. Clin Breast Cancer. 2018;18(5):e919-e26. https://doi.org/10.1016/j.clbc.2018.03.014.

35. Guan Z-Z, Li QL, Feng F, et al. Superior efficacy of a Cremophor-free albumin-bound paclitaxel compared with solvent-based paclitaxel in Chinese patients with metastatic breast cancer. Asia-Pacific J Clin Oncol. 2009;5(3):165-74. https://doi.org/10.1111/j.1743-7563.2009.01235.x

\section{Publisher's Note}

Springer Nature remains neutral with regard to jurisdictional claims in published maps and institutional affiliations.

Ready to submit your research? Choose BMC and benefit from:

- fast, convenient online submission

- thorough peer review by experienced researchers in your field

- rapid publication on acceptance

- support for research data, including large and complex data types

- gold Open Access which fosters wider collaboration and increased citations

- maximum visibility for your research: over $100 \mathrm{M}$ website views per year

At BMC, research is always in progress.

Learn more biomedcentral.com/submissions 